\title{
Influence of personality on caregiver's burden, depression and distress related to the BPSD ${ }^{\dagger}$
}

\author{
Graça Melo ${ }^{1}$, João Maroco ${ }^{2}$ and Alexandre de Mendonça ${ }^{3}$ \\ ${ }^{1}$ Escola Superior de Enfermagem de Lisboa, Universidade de Lisboa, Portugal \\ ${ }^{2}$ ISPA, Instituto Universitário, Portugal \\ ${ }^{3}$ Laboratório de Neurociências e Serviço de Neurologia, Instituto de Medicina Molecular e Faculdade de Medicina, Universidade de Lisboa, \\ Portugal \\ Correspondence to: G. Melo, E-mail: graca.melo@esel.pt \\ ${ }^{\dagger}$ Name of institutions at the research was conducted: Hospital de Santa Maria (Lisbon) and Memoclínica (Lisbon).
}

\begin{abstract}
Objective: We hypothesize that the personality influences the caregiver's depression, burden and distress related to BPSD.

Subjects and methods: Participants were 105 consecutive patients with dementia and their family caregivers, living at home, attending a Dementia Clinic. A cross-sectional design was used with an applied a structured interview at home. Comprehensive assessments included: personality (NEO-FFI), burden (ZBI), depression (CES-D) and distress related to BPSD (NPI-distress). Statistical Path analysis was used to study the hypothetical causal and mediating effects between independent and criterion variables.

Results: Neuroticism increased, whereas extraversion decreased, both caregiver's depression and burden. Agreeableness was also found to decrease the burden. The personality characteristics only indirectly influenced the caregiver's distress related to BPSD.

Conclusion: These results reinforce the importance of including personality as an individual resource of the caregiver in the conceptual models and research on caregiving. Assessment of caregiver's personality characteristics should be taken into account for the planning of intervention programs. Copyright (C) 2011 John Wiley \& Sons, Ltd.
\end{abstract}

Key words: caregiver; dementia; personality; burden; depression; distress

History: Received 24 August 2010; Accepted 29 November 2010; Published online in Wiley Online Library

(wileyonlinelibrary.com).

DOI: $10.1002 /$ gps.2677

\section{Introduction}

Dementia is a syndrome characterized by an acquired and global cognitive and functional decline, as well as behavioural and psychological symptoms. A study calculated that 24.3 million people live with dementia, with 4-6 million new cases every year in the world (Ferri et al., 2005). In the European Union, 6 million persons live with dementia (Alzheimer Europe, 2006). The costs of Dementia in Europe increase with disease severity (Jönsson and Wimo, 2009) and was estimated to be $€ 130$ billion, of which $56 \%$ were costs associated with informal care (Alzheimer Europe, 2008). Family caregivers have often been referred to as the 'backbone' of long term care because most of patients are cared at home by relatives, usually spouses, and these play a key role in care (Feinberg and Pilisuk, 1999).

Caring someone with dementia, sometimes $24 \mathrm{~h}$ per day, is a stressful and demanding activity that affects caregiver's psychological and physical well-being (Schultz et al., 1995; Pinquart and Sorensen, 2003; Vitaliano et al., 2003; Pinquart and Sorensen, 2007; Adams et al., 2008) and the caregiver is at high risk for burden, social isolation and depressive symptoms (Schultz et al., 1995; Sherwood et al., 2005). The objective and subjective burden of care and psychiatric morbidity, namely depression, are associated with specific characteristics of the caregiver (Sink et al., 2006) and influence some factors of the own caregiver, as the caregiver's coping strategies to deal with the symptoms 
and meaning of the illness (Vugt et al., 2004). However, it has been suggested that interventions to improve coping strategies only offer moderate success (Brodaty et al., 2003) and there is a call for a more individualized approach with an increase in knowledge of the differences and variability in caregivers (Mittelman et al., 2004; Carratero et al., 2007).

Behavioural and psychological symptoms of dementia (BPSD) affect the majority of patients at same point in the progression of the disease (Lyketsos et al., 2002; Engelborghs et al., 2005). These BPSD occur in a dynamic process involving the patient, the family caregiver and their environment. They are known to be more stressful to caregivers than cognitive or functional decline, because are felt as the most difficult to manage (Donaldson et al., 1998; Hooker et al., 2002; Vugt et al., 2003; Matsumoto et al., 2007) and have a negative impact on the relationships between the caregiver, patient and family (Lyons et al., 2002). It has been reported that caregivers differ in their emotional responses to BPSD even when facing similar problems and the caregiver's perception of patient's problems is more important than problem behaviour 'per se' (Zarit, 1996; Vugt et al., 2005), furthermore, caregivers can interpret poorly and react inadequately to BPSD (Paton et al., 2004).

All this evidence highlights the importance of subjective factors and individual differences among caregivers in the caring experience and in coping with the demands posed by the patient with dementia. The personality characteristics affect the processes that individuals use to appraise stressful events and predispose them to cope in certain ways when they confront these events (Hooker et al., 1994; McCrae and Costa, 2006, p. 219; Carver and Connor-Smith, 2010). Personality also had significant direct and indirect effects on mental health and direct effects on physical health (Hooker et al., 1998; Jang et al., 2004). In the present study, we hypothesize that the personality influences the caregiver's depression, burden and distress associated with the behavioural and psychological symptoms of patients with dementia. The inclusion of caregiver's personality traits in the caregiving models would increase the knowledge of caregivers' role and hopefully contribute to improve the quality of life of the caregiver and the patient.

\section{Materials and methods}

\section{Participants}

The participants were 105 patients with dementia, living at home, and their family caregivers, consecu- tively recruited at a Dementia Clinic. Dementia was diagnosed according to DSM-IV criteria (American Psychiatric Association, 2000).

We defined caregiver as the family member most responsible for day-to-day decisions and care of the patient. Requirements for participations were that the caregivers had been in the caregiving role for a minimum of six months, and spending at least $2 \mathrm{~h}$ per day caring for the relative. Caregivers with abnormal mini-mental status examination (MMSE) scores were excluded (see below).

\section{Procedures}

Caregivers were administered a structured interview at home. In all cases, the interviews were conducted by the same trained interviewer. The project was approved by the Research Ethics Committee of the Hospital Universitário de Santa Maria, Lisbon. Written informed consent was obtained from all subjects, after full explanation of the procedures.

\section{Patient and caregiver measures}

Sociodemographic variables (age, gender, education) were registered during an interview with the caregiver.

Mini-mental status examination (MMSE) (Folstein et al., 1975; Guerreiro, 1998) is one of the most widely used screening instruments for dementia, and provides a total score ranging from 0 to 30 , with lower scores indicative of greater cognitive impairment. It was administered to the patients to obtain an overall level of current cognitive function, and to family caregivers to rule out cognitive deficits.

\section{Patient measures}

The stage of dementia was evaluated with global deterioration scale (GDS) (Reisberg et al., 1982; Leitão et al., 2008), a well-established scale used to measure the severity of functional and cognitive deficits in dementia. Scores range from 1 (no cognitive decline) to 7 (very severe cognitive decline).

The BPSD was measured with the neuropsychiatric inventory (NPI) (Cummings et al., 1994; Leitão and Nina, 2008). The NPI rates symptoms in 12 domains: delusions, hallucinations, agitation/aggression, depression/dysphoria, anxiety, euphoria/elation, apathy, disinhibition, irritability/lability, aberrant motor behaviour, sleeping and eating. In each domain, the 
informant was asked if the behaviour represent a change from that shown by the patient before the onset dementia and had been present during the previous month. If an affirmative answer was obtained from a screening question, specific neuropsychiatric symptoms, in each behavioural domain, were explored. On the basis of scoring the frequency ( 1 'sometimes' to 4 'very often') and the severity ( 1 'mild' to 3 'severe') of each neuropsychiatric symptom, a composite score for each domain was determined as the product of the frequency and severity subscores (maximum, 12). The total NPI score was calculated by adding all composite scores of each domain (range between 0 and 120).

\section{Family caregiver measures}

The neuropsychiatric inventory distress (NPI-D) (Kaufer et al., 1998; Leitão and Nina, 2008) provides a quantitative measure of the distress experienced by caregivers in relation to the individual symptom domains assessed by the NPI. After rating each symptom domain of the NPI, caregivers are asked to grade the emotional and psychological distress that they experienced in relation to the symptom on a 6point scale: 0 (not at all distressing) to 5 (extremely distressing). The maximum total NPI-D score is 60 .

The Zarit burden interview (ZBI) is a 22-item, self report measure of perceived burden. The instrument measures caregivers' psychological health, emotional well-being, social and family life, finances, and degree of control over one's life. Each question is scored on a 5 -point Likert scale. Total scores range from 0 (low burden) to 88 (high burden) (Zarit et al., 1980; Gonçalves-Pereira et al., 2010).

Depression of the caregiver was measured with the Centre for Epidemiologic Studies-depression scale (CES-D) (Radloff, 1977; Gonçalves and Fagulha, 2003). It is a 20 -item scale used to assess the overall level of depression experienced in the past week. Responses are provided along a 4-point Likert-type scale range from 0 (rarely or once a time) to 3 (most or all the time). Total scores ranged 0-60.

The Portuguese version of the NEO five-factor inventory (NEO-FFI) (Costa and McCrae, 1992; Lima and Simões, 2003), a short form of the personality inventory-revised (NEO-PI-R), with 60 items, was used to measure the traits of personality: neuroticism, extraversion, openness to experience, agreeableness and conscientiousness. Each question is scored on a 5point Likert scale, ranging from 0 to 4 ; the total scores, in each dimension, range from 0 to 48 .

\section{Statistical analysis}

A cross-sectional design was used. Path Analysis was used to test hypothetical causal and mediation effects between personality traits and depression, burden and distress related to the BPSD. Descriptive statistical analysis was performed with PASW, v. 18 (SPSS Inc., Chicago, IL). Path analysis was performed with AMOS 18 (SPSS Inc.). Statistical significant effects were assumed for $p<0.05$.

\section{Results}

The characteristics of family caregivers and patients are summarized in Table 1. The caregivers were mostly female, but there were a noteworthy number of male caregivers.

Regarding the five dimensions of personality, the following mean $\pm \mathrm{SD}$ scores were obtained for the caregivers: neuroticism: $25.7 \pm 8.3$; extraversion: $27.0 \pm$ 6.8; openness: $25.7 \pm 5.6$; agreeableness: $33.1 \pm 4.0$; conscientiousness: $37.0 \pm 4.8$. The mean of distress related to behavioural and psychological symptoms was $15.2 \pm 10.3$.

The number of behavioural symptoms and the scores in the NPI (frequency $\times$ severity) and NPIdistress items are shown in Table 2. The symptoms most frequent and with higher total score (frequency $\times$ severity) were apathy $(79.0 \%, 5.2 \pm 4.2)$ and agitation $(62.9 \%, 3.1 \pm 3.7)$. Caregivers also showed the highest scores at NPI-distress for the same items, apathy $(2.7 \pm 1.9)$ and agitation $(2.3 \pm 2.1)$.

We developed a path model (see Figure 1) in which hypothetical direct effects between caregiver's personality dimensions and caregiver's distress were tested as well as indirect, mediated, effects of depression and burden over caregiver's distress. Path analysis showed that the caregiver's personality dimensions influence caregiver's depression and burden. Neuroticism increased depression $(\beta=0.63, p<0.001)$, whereas extraversion decreased depression $(\beta=-0.24$, $p<0.001)$. Neuroticism also increased the caregiver's burden $(\beta=0.42, p<0.001)$, whereas extraversion $(\beta=-0.18, p=0.04)$ and agreeableness $(\beta=-0.20$, $p=0.03)$ decreased the caregiver's burden.

No dimension of personality influenced directly caregiver's distress related to the BPSD. However, since the burden increased the distress related to the BPSD $(\beta=0.51, p<0.001)$, neuroticism would indirectly increase the caregiver's distress mediated by burden, whereas extraversion and agreeableness would decrease the caregiver's distress also through burden. The 
Table 1 Characteristics of family caregivers and patients

\begin{tabular}{|c|c|c|c|c|}
\hline & \multicolumn{2}{|c|}{ Caregivers } & \multicolumn{2}{|c|}{ Patients } \\
\hline & $n(\%)$ & Mean \pm SD & $n(\%)$ & Mean \pm SD \\
\hline \multicolumn{5}{|l|}{ Gender } \\
\hline Female & $72(68.6)$ & & $58(55.2)$ & \\
\hline Male & 33 (31.4) & & 47 (44.8) & \\
\hline Age (years) & & $67.0 \pm 12.5$ & & $75.4 \pm 8.1$ \\
\hline Education (years) & & $7.9 \pm 4.6$ & & $6.3 \pm 4.4$ \\
\hline \multicolumn{5}{|l|}{ Relationship } \\
\hline Spouses & 79 (75.2) & & & \\
\hline Children & 17 (16.2) & & & \\
\hline Others & $9(8.6)$ & & & \\
\hline Living together & $100(95.2)$ & & & \\
\hline Years of care & & $4.2 \pm 3.2$ & & \\
\hline Hours of contact/day & & $12.0 \pm 8.7$ & & \\
\hline \multicolumn{5}{|l|}{ Type of Dementia } \\
\hline AD & & & $64(61)$ & \\
\hline FTD & & & $18(17.1)$ & \\
\hline DLB & & & $7(6.7)$ & \\
\hline $\mathrm{VaD}$ & & & 7 (6.7) & \\
\hline Others & & & $9(10.7)$ & \\
\hline MMSE & & & & $13.9 \pm 7.9$ \\
\hline \multicolumn{5}{|c|}{ Severity of dementia (GDS) } \\
\hline Mild/moderate & & & 66 (62.9) & \\
\hline Severe/very severe & & & $39(37.1)$ & \\
\hline NPI (Total) & & & & $26.4 \pm 17.1$ \\
\hline \multicolumn{5}{|l|}{ Personality (NEO-FFI) } \\
\hline Neuroticism & & $25.7 \pm 8.3$ & & \\
\hline Extraversion & & $27.0 \pm 6.8$ & & \\
\hline Openness & & $25.7 \pm 5.6$ & & \\
\hline Agreeableness & & $33.1 \pm 4.0$ & & \\
\hline Conscientiousness & & $37.0 \pm 4.8$ & & \\
\hline Depression (CES-D) & & $18.6 \pm 11.4$ & & \\
\hline Burden (ZBI) & & $31.8 \pm 14.3$ & & \\
\hline NPI-distress & & $15.2 \pm 10.3$ & & \\
\hline
\end{tabular}

AD, Alzheimer's disease; FTD, frontotemporal dementia; DLB, dementia with Lewy bodies; VaD, vascular dementia; MMSE, mini-mental state examination; GDS, global deterioration scale; NPI, neuropsychiatric inventory; CES-D, Centre for Epidemiologic Studies-depression scale; ZBI, Zarit burden interview; NPI-D, neuropsychiatric inventory-distress.

caregiver's depression did not influence the distress related to the BPSD. Overall, the model (Figure 1), explained $42 \%$ of the variance in the distress related to the BPSD $\left(R^{2}=0.42, p<0.001\right)$.

\section{Discussion}

The main finding of the present study is that several dimensions of caregiver's personality strongly influenced burden and depressive symptoms of the caregiver. Neuroticism enhanced the caregiver's burden and depression. In contrast, extraversion and agreeableness both decreased the caregiver's burden, and extraversion also attenuated the caregiver's depression.

High levels of neuroticism were a strong predictor of both caregiver burden and depression, in accordance with previous studies (Bookwala and Schulz, 1998; Jang et al., 2004; Helmes et al., 2005; Shurgot and
Knight, 2005; Campbell et al., 2008). This trait of personality is an indicator of global individual propensity to experience negative influences. Individuals who score high in this dimension tend to be 'for emotional imbalance, unrealistic ideas, desires and needs excessive or inappropriate coping responses', while those who score low are 'calm, relaxed, resilient, secure, non-emotive, self-satisfied' (Lima and Simões, 2003, p. 17). Caring for dementia sufferers is a highly demanding task both emotionally and physically. Thus, an irritable and sometimes hostile caregiver who easily blames others for the difficulties he/she is experiencing can hardly adapt to a situation of permanent stress such as that of caregiving. Furthermore, caregiver personality characteristics may influence the success of intervention programs. Jang et al. (2004) found that a comprehensive psychosocial intervention with counselling, support and consultation was beneficial to caregivers, as compared to the 
Influence of personality on caregiving

Table 2 Number of patients with symptoms in NPI, scores in NPI (frequency $\times$ severity) and in NPI-distress

\begin{tabular}{lccc}
\hline \multirow{2}{*}{ NPI domains } & \multicolumn{3}{c}{ Caregivers } \\
\cline { 2 - 3 } & $\begin{array}{c}\text { PPI (symptom) } \\
n(\%)\end{array}$ & $\begin{array}{c}\text { NPI (frequency } \times \text { severity) } \\
\text { Mean } \pm \text { SD }\end{array}$ & $\begin{array}{c}\text { NPI (distress) } \\
\text { Mean } \pm \text { SD }\end{array}$ \\
\hline Delusions & $48(45.7)$ & $2.1 \pm 3.0$ & $1.4 \pm 1.9$ \\
Hallucinations & $25(23.8)$ & $0.8 \pm 2.0$ & $0.6 \pm 1.4$ \\
Agitation/aggression & $66(62.9)$ & $3.1 \pm 3.7$ & $2.3 \pm 2.1$ \\
Depression/dysphoria & $46(43.8)$ & $2.2 \pm 3.5$ & $1.4 \pm 1.8$ \\
Anxiety & $43(41.0)$ & $2.5 \pm 3.8$ & $1.4 \pm 1.9$ \\
Euphoria/elation & $11(10.5)$ & $5.4 \pm 1.6$ & $0.3 \pm 1.0$ \\
Apathy & $83(79.0)$ & $1.1 \pm 2.9$ & $2.6 \pm 1.9$ \\
Disinhibition & $19(18.1)$ & $2.1 \pm 3.3$ & $0.6 \pm 1.5$ \\
Irritability/lability & $49(46.7)$ & $2.8 \pm 4.2$ & $1.6 \pm 2.0$ \\
Aberrant motor behaviour & $40(38.1)$ & $2.6 \pm 3.3$ & $1.1 \pm 1.7$ \\
Sleep & $23(21.9)$ & $26.4 \pm 1.2$ & $1.9 \pm 1.8$ \\
Appetite & $33(31.4)$ & & $1.0 \pm 1.7$ \\
Total & - & & $15.2 \pm 10.3$ \\
\hline
\end{tabular}

NPI, neuropsychiatric inventory.

usual care. However, the caregivers with low neuroticism showed a decrease in the depression levels, but the caregivers with high neuroticism did not.

Extraversion corresponds to individual propensity to social interaction and activities. People with high scores in this construct tend to be 'sociable, active, talkative, person-oriented, optimistic' while those who score low tend to be 'cold, reserved, formal, taskoriented, retiring, serious' (Lima and Simões, 2003, p. 18). Caregiver's extraversion decreased both burden

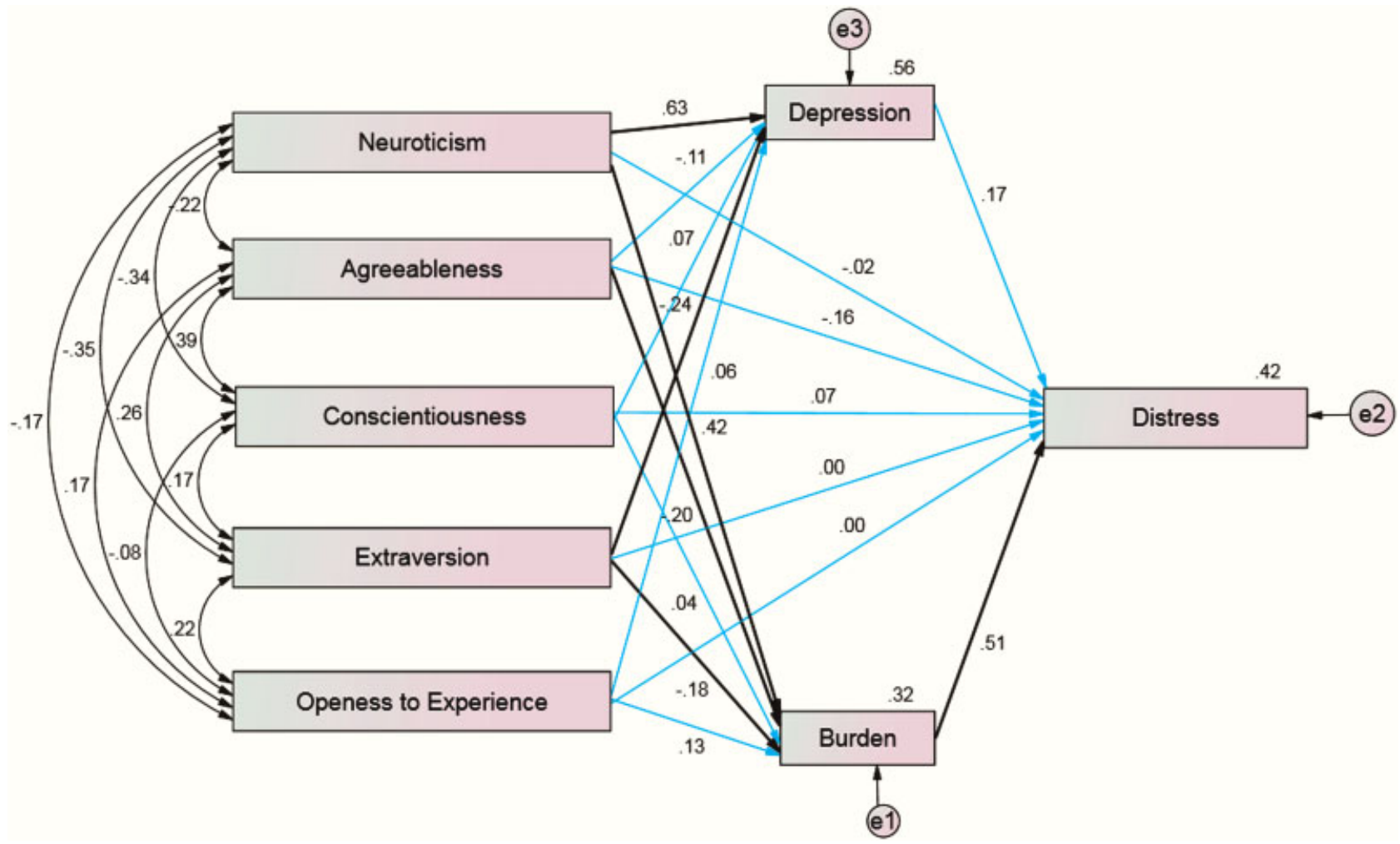

Figure 1 Path Model of the standardized direct and indirect effects of the personality dimensions, depression and burden on caregiver's distress. Bold paths are statistically significant for $p<0.05$ level; greyed paths are not significant. 
and depression. The tendency to isolation and low optimism are factors that facilitate depression (Márquez-González et al., 2009). We could speculate that caregivers more focused on carrying out tasks rather than on the well being of his/her relative as a 'person', with needs which transcend the mere carrying out of tasks, tend to feel burdened and overwhelmed by the difficulties involved in caregiving.

Agreeableness is an indicator of the way in which a person thinks and behaves which can be characterized as compassion versus antagonism. A high score means someone who is 'soft-hearted, good-natured, trusting, helpful, forgiving, gullible'; while low scores are shown by people who tend to be 'cynical, rude, suspicious, uncooperative, vengeful, ruthless, irritable, manipulative' (Lima and Simões, 2003, p. 19). Caregiver's agreeableness decreased the burden. Therefore, caregivers with lower agreeableness scores may have had greater difficulty in recognizing the illness and suffering of the other, and in establishing a cooperative relationship with the patient as well as ascribing a positive meaning to his/her role as a caregiver.

Contrary to the initial hypothesis that the dimensions of personality might directly influence the distress felt by the caregiver in relation to BPSD, neuroticism, extraversion and agreeableness could only influence distress related to BPSD through an indirect effect, mediated by the caregiver's burden. Caregivers with high levels of neuroticism and burden might have an increased propensity of reporting high levels of distress associated with the BPSD, because they could respond to behavioural symptoms based on both the behaviours and their own stress. BPSD are the result of a dynamic and complex circular process (Campbell et al., 2008) between the caregiver, the patient and the environment (Zarit, 1996). The inadequate response of the caregiver could exacerbate the patient's symptom, and consequently worsen his/her own distress. Various studies have mentioned that caregivers with high levels of neuroticism use maladaptative strategies in dealing with patients' behaviours (Vugt et al., 2003; Chappell and Dujela, 2009). They primarily approach the patient with impatience, irritation or anger, and try to manage behavioural problems by confronting or ignoring the patient (Vugt et al., 2004). Some caregivers tend to respond with irritability, criticism and confrontation to patients' recurrent forgetfulness, mistakes in performing daily tasks, lack of initiative in engaging in activities, and low expression of affection towards the presence of relatives and friends. Consequently, they frequently cause a mirror-response of aggressiveness, agitation, or on the contrary of disquiet and dismay in the patient (Zarit, 1996; Vugt et al., 2004). In clinical practice, one usually finds caregivers with difficulties in understanding and tolerating ideas expressed in delirium or in the hallucinations of their patients. Permanent confrontation and argumentation against the inveracity of the patient 'truth', promotes and worsens aggressive, accusatory and distrustful behaviour in relation to his/her caregiver (Zarit, 1996). Other studies have shown that many caregivers believe that symptoms are under the patient's control and that he/she can improve them (Donaldson et al., 1998; Paton et al., 2004). Caregivers who resist to equating symptoms with dementia suggest that they have a different understanding of dementia, or are trying to minimize or deny the effects of this illness (Paton et al., 2004). On the contrary, caregivers who realize that behaviours have a meaning which is beyond the control of the dementia sufferer can consciously control their responses (Campbell et al., 2008). Results gathered in the present study do not deny that personality characteristics do have importance in the distress felt by caregivers in response to BPSD of their patients, but suggest that these influences are essentially mediated by other factors, in particular by burden.

The mechanisms whereby personality domains influence caregiver's burden and depression could involve the preference for different coping strategies. Low scores of neuroticism and high scores of extraversion were associated with emotional-focused coping and problem-focused coping, and agreeableness was positively associated with social support coping and negatively associated with emotional-focused coping (Hooker et al., 1994). However, others suggested that the personality profile does not seem to influence systematically the coping ability (Renzetti et al., 2001). A recent study emphasizes that neuroticism is a predictor of negative emotion coping and not of the use of specific coping strategies (Chappell and Dujela, 2009). In turn, it was found that high burdened relatives use more emotional-focused coping strategies, while less burdened relatives used more problemsolving approaches to caregiving demands (Papastavrou et al., 2007). Importantly, caregivers who were identified as less responsive and less psychological available were shown to have a coping style that was correlated to shorter survival time in persons with dementia (McClendon et al., 2004). It was also found that the use of maladaptative emotional coping strategies is a predictive factor of burden (Papastavrou et al., 2007), psychiatric morbidity and, in particular, depression (Schultz et al., 1995). Caregivers with nonadapters characteristics (more neurotic and depressed; more burdened and feeling less competent) report more behavioural symptoms in general and 
more hyperactivity symptoms over time, as a direct response to the caregiver's attitudes such as impatience or irritation (Vugt et al., 2004).

It has been proposed that the factors associated with the caregiver have greater impact on depression and burden than those relating to the patient (Zanetti et al., 1998; Campbell et al., 2008). In this context, personality must be envisaged as an important individual resource which influences the way in which the caregiver ascribes meaning to illness and reacts to caregiving. For this reason, personality is a decisive factor influencing the outcomes, both in the patient and in the caregiver. The need to understand variability and differences among caregivers is thus of paramount importance in unveiling the reasons which lead caregivers to respond distinctly to similar situations.

Limitations of the study must be recognized, namely the small sample size and the convenience sampling may restrain the generalization of the results. An important advantage of the study is that the domains of personality were systematically evaluated in the caregivers. We showed that personality influences the caregiver's depression and burden, which in turn are mediators of distress. These findings reinforce the importance of including personality as an individual resource of the caregiver in the conceptual models and research on caregiving, because it decisively influences the outcomes in both the caregiver and the patient. In clinical practice, assessment of caregiver's personality characteristics should be taken into account for the planning of intervention programs, since the whole of the caregiving process is shaped by the characteristics of caregivers and patients, their previous and current relationships, illness-related variables, social networks and ways of coping. The above mentioned study of Jang et al. (2004) gives an example of how the levels of neuroticism might lead to individualization of treatment, suggesting that caregivers with high neuroticism would require an additional treatment beyond psychosocial intervention to improve their levels of depression. Since the personality is related to coping in the caregiver situation and coping strategies are modifiable (Hooker et al., 1994), the workup of coping strategies in order to reach more adaptative and successful approaches is another example where interventions should consider information about personality characteristics. To be sure, assessment of caregivers remains a challenging area, both in research and clinical practice (Brodaty, 2007).

\section{Conflict of interest}

None declared.
Key Points

- Dimensions of caregiver's personality strongly influenced burden and depression of the caregiver; neuroticism had a negative influence, whereas extraversion and agreeableness had a favourable effect on the caregiver.

- The personality characteristics only indirectly affected the caregiver's distress related to BPSD, namely through the burden.

- The model proposed explained $42 \%$ of the variance in the caregiver's distress related to the BPSD.

- Personality, as an individual resource of the caregiver, must be taken into account in the research on caregiving and in the planning of intervention programs.

\section{Description of authors' roles}

Alexandre de Mendonça and Graça Melo designed the study. Alexandre de Mendonça coordinated data collection and Graça Melo collected the data. Statistical analysis was carried out by João Maroco, Alexandre de Mendonça and Graça Melo. The initial draft was written by Graça Melo. All authors revised the manuscript critically and approved the final version for publication.

\section{Acknowledgements}

The authors would like to thank Dr. Ana Verdelho and Dr. Frederico Simões do Couto for assistance with data collection and Prof. Manuela Guerreiro for helpful suggestions. The support from Memoclinica and Hospital de Santa Maria is also acknowledged. Most of all, we would like to thank all caregivers and patients for their invaluable collaboration.

\section{References}

Adams K, McClendon M, Smyth K. 2008. Personal losses and relationship quality in dementia caregiving. Dementia 7: 301-319.

Alzheimer Europe. 2006. Dementia in Europe. Alzheimer Europe: Luxembourg; 22. Alzheimer Europe. 2008. Dementia in Europe. Alzheimer Europe: Luxembourg; 69. American Psychiatric Association. 2000. Diagnostic and Statistical Manual of Mental Disorders: DSM-IV, 4th edn. American Psychiatric Association: Washington, DC.

Bookwala J, Schulz R. 1998. The role of neuroticism and mastery in spouse caregiver's assessment of and response to a contextual stressor. J Gerontol B Psychol Sci Soc Sci 53: $155-164$

Brodaty H. 2007. Meaning and measurement of caregiver outcomes. Int Psychogeriatr 19: 1-19. 
Brodaty H, Green AG, Koschera A. 2003. Meta-analysis of psychosocial interventions for caregivers of people with dementia. J Am Geriatr Soc 51: 1-8.

Campbell P, Wright J, Oyebode J, et al. 2008. Determinants of burden in those who care for someone with dementia. Int J Geriatr Psychiatry 23: 1078-1085.

Carratero S, Garces J, Redenas F. 2007. Evaluation of the home help service and the impact on the informal caregiver's burden. Int Psychogeriat 22: 738-749.

Carver CS, Connor-Smith J. 2010. Personality and coping styles. Annu Rev Psychol 61: 679-704.

Chappell NL, Dujela N. 2009. Who copes how? Int J Aging Hum Dev 69: 221-224.

Costa P, McCrae R. 1992. The NEO PI-R/NEO-FFI Manual Supplement. Psychological Assessments Resources: Odessa.

Cummings JL, Mega M, Gray K, et al. 1994. The neuropsychiatric inventory: comprehensive assessment of psychopathology in dementia. Neurology 44: 2308-2314.

Donaldson C, Tarrier N, Burns A. 1998. Determinants of career stress in Alzheimer's disease. Int J Geriatr Psychiatry 13: 248-256.

Engelborghs S, Maertens K, Nagels G, et al. 2005. Neuropsychiatric symptoms of dementia: cross-sectional analysis from a prospective, longitudinal Belgian study. Int J Geriatr Psychiatry 20: 1028-1037.

Feinberg L, Pilisuk L. 1999. Survey of Fifteen States Caregivers Support Programs. Family Caregiver Alliance: San Francisco.

Ferri CP, Prince M, Brayne C, et al. 2005. Global prevalence of dementia: a Delphi consensus study. Lancet 6: 2112-2117.

Folstein MF, Folstein SE, McHugh PR. 1975. Mini-mental state: a practical method for grading the cognitive state of patients for the clinicians. J Psychiatr Res 12: 189-198.

Gonçalves B, Fagulha T. 2003. Escala de Depressão do Centro de Estudos Epidemiológicos. In Avaliação Psicológica: Instrumentos Validados para a População Portuguesa, Gonçalves M, Simões M, Almeida L, Machado C (eds). Quarteto: Coimbra; $32-43$.

Gonçalves-Pereira M, Carmo P, Silva A, et al. 2010. Caregiving experiences and knowledge about dementia in Portuguese clinical outpatient settings. Int Psychogeriatr 22: 270-280.

Guerreiro M. 1998. Contributo da Neuropsicologia para o Estudo das Demências. Dissertação de Doutoramento, Faculdade de Medicina de Lisboa, Ciências Biomédicas; 13-15, 37-61.

Helmes E, Green B, Almeida O. 2005. Individual differences in the experience of burden in caring for relatives with dementia: role of personality and mastery. Australas J Ageing 24: 202-206.

Hooker K, Frazier LD, Monahan DJ. 1994. Personality and coping among caregivers of spouses with dementia. Gerontologist 34: 386-392.

Hooker K, Monahan DJ, Bowman SR, et al. 1998. Personality counts a lot: predictors of mental and physical health of spouses caregivers in two disease groups. J Gerontol B Psychol Sci Soc Sci 2: 73-85.

Hooker K, Bowman SR, Coehlo DP, et al. 2002. Behavioral change in persons with dementia: relationships with mental and physical health of caregivers. J Gerontol B Psychol Sci Soc Sci 57: 453-460.

Jang Y, Clay OJ, Roth DL. 2004. Neuroticism and longitudinal change in caregiver depression: impact of a spouse-caregiver intervention program. Gerontologist 44 311-317.

Jönsson L, Wimo A. 2009. The cost of dementia in europe: a review of the evidence, and methodological considerations. Pharmacoeconomics 27: 391-403.

Kaufer DI, Cummings JL, Christine D, et al. 1998. Assessing the impact of neuropsychiatric symptoms in Alzheimer's disease: the Neuropsychiatric Inventory Caregiver Distress Scale. J Am Geriatr Soc 46: 210-215.

Leitão O, Nina A. 2008. Inventário Neuropsiquiátrico. In Escalas e Testes na Demência, de Mendonça A, Guerreiro M (eds). 3 edn. Grupo de Estudos do Envelhecimento Cerebral e Demências: Lisboa; 77-97.

Leitão O, Nina A, Monteiro I. 2008. Escala de Deterioração Global. In Escalas e Testes na Demência, de Mendonça A, Guerreiro M (eds). 3 edn. Grupo de Estudos do Envelhecimento Cerebral e Demências: Lisboa; 11-16.

Lima M, Simões A. 2003. Inventário da personalidade NEO Revisto (NEO-PI-R). In Avaliação Psicológica: Instrumentos Validados para a População Portuguesa, Gonçalves M, Simões M, Almeida L, Machado C (eds). Quarteto: Coimbra; 16-32.
Lyketsos CG, Lopez O, Jones B, et al. 2002. Prevalence of neuropsychiatric symptoms in dementia and cognitive impairment: results from the cardiovascular health study. JAMA 25: 1475-1483.

Lyons KS, Zarit SH, Sayer AG, Whitlatch CJ. 2002. Caregiving as a dyadic process: perspectives from caregiver and receiver. J Gerontol B Psychol Sci Soc Sci 57: 195204.

Márquez-González M, Baltar AL, Puente CP, Romero-Moreno R. 2009. El optimismo como factor moderador de la relación entre el estrés y la depresión de los cuidadores informales de personas mayores dependientes. Rev Esp Geriatr Gerontol 44: 251-255.

Matsumoto N, Ikeda M, Fukuhara R, et al. 2007. Caregiver burden associated with behavioral and psychological symptoms of dementia in elderly people in the local community. Dement Geriatr Cogn Disord 23: 219-224.

McClendon MJ, Smyth KA, Neundorfer MM. 2004. Survival of persons with Alzheimer's disease: caregiver copping matters. Gerontologist 44: 508-519.

McCrae RR, Costa PT. 2006. Personality in Adulthood - A Five-Factor Theory Perspective, 2nd edn. The Guildford Press: New York.

Mittelman M, Roth D, Haley W, Zarit S. 2004. Effects of caregiver intervention on negative caregiver appraisals of behavior problems in patients with Alzheimer's disease: results of a randomized trial. J Gerontol B Psychol Sci Soc Sci 59: 27-34.

Papastavrou E, Kalokerinou A, Papacostas SS, et al. 2007. Caring for a relative with dementia: family caregiver burden. J Adv Nursing 58: 446-457.

Paton J, Johston K, Katona C, Livingston G. 2004. What causes problems in Alzheimer's disease: attributions by caregiver. A qualitative study. Int J Geriatr Psychiatry 19: 527-532.

Pinquart M, Sorensen S. 2003. Differences between caregivers and noncaregivers in psychological health and physical health: meta-analysis. Psychol Aging 18: 250-267.

Pinquart I, Sorensen S. 2007. Correlates of physical health of informal caregivers: a meta-analysis. J Gerontol B Psychol Sci Soc Sci 62: 126-137.

Radloff L. 1977. The CES-D scale: A self-report depression scale for research in general population. Appl Psychol Meas 1: 385-401.

Reisberg B, Ferris SH, Leon MJ, Crook T. 1982. The global deterioration scale for assessment of primary degenerative dementia. Am J Psychiatry 139: 1136-1139.

Renzetti C, Iacono S, Pinelli L, et al. 2001. Living with dementia: is distress influenced by carer personality? Arch Gerontol Geriatr 7: 333-340.

Schultz R, O'Brien A, Bookwala J, Fleissner K. 1995. Psychiatric and physical morbidity effects of dementia caregiving: prevalence, correlates and causes. Gerontologist 35: 771-791.

Sherwood P, Given C, Given B, Von Eye A. 2005. Caregiver burden and depressive symptoms: analyses of common outcomes in caregivers of elderly patients. J Aging Health 17: 125-147.

Shurgot GR, Knight BG. 2005. Influence of neuroticism, ethnicity, familism, and social support on perceived burden in dementia caregivers: pilot test of transactional stress and social support model. J Gerontol B Psychol Sci Soc Sci 60: 331334.

Sink KM, Covinsky KE, Barnes DE, et al. 2006. Caregiver characteristics are associated with neuropsychiatric symptoms of dementia. J Am Geriatr Soc 54: 796-803.

Vitaliano PP, Scanan JM, Zhang J. 2003. Is caregiving hazardous to one's physical health? A meta-analysis. Psychol Bull 129: 946-972.

Vugt ME, Stevens F, Aalten P, et al. 2003. Behavioural disturbances in dementia and quality of the marital relationship. Int J Geriatr Psychiatry 18: 149-154.

Vugt ME, Stevens F, Aalten P, et al. 2004. Do caregiver management strategies influence patient behaviour in dementia? Int J Geriatr Psychiatry 19: 85-92.

Vugt ME, Stevens F, Aalten P, et al. 2005. A prospective study of the effects of behavioural symptoms on the institutionalization of patients with dementia. Int Psychogeriatr 17: 577-586.

Zanetti O, Frisoni GB, Bianchetti A, et al. 1998. Depressive symptoms of alzheimer caregivers are mainly due to personal rather than patient factors. Int J Geriatr Psychiatry 13: 358-367.

Zarit SH. 1996. Behavioral disturbances of dementia and caregivers issues. Int Psychogeriatr 8: 263-268.

Zarit SH, Reever KE, Bach-Peterson J. 1980. Relatives of the impaired elderly: correlates of feelings of burden. Gerontologist 20: 649-655. 